\title{
Editorial: Behavior Science for the Public Welfare
}

\section{Donald A. Hantula ${ }^{1}$}

Published online: 27 August 2019

(C) Association for Behavior Analysis International 2019

Near the end of the Second World War, U.S. president Franklin Roosevelt commissioned Vannevar Bush, a leading scientist and engineer of the $20^{\text {th }}$ century who directed U.S. government research during the War, to write a report on the future of postwar science and science policy in the United States. The report, Science-The Endless Frontier (Bush, 1945), made bold and sweeping recommendations that set the stage for the current model of federal funding of scientific research, government investment in training and supporting future scientists, and the founding the National Science Foundation. The report not only introduced the term "basic research" into common parlance, it also expanded the definition to refer to both addressing the demands for practical innovations and to promoting scientific curiosity (Pielke, 2010).

Bush (1945) asserted that scientific progress was essential to public welfare in the post-war world. Indeed, in the third chapter of the report, "Science for the Public Welfare" he asserted:

Basic research leads to new knowledge. It provides scientific capital. It creates the fund from which the practical applications of knowledge must be drawn. New products and new processes do not appear full-grown. They are founded on new principles and new conceptions, which in turn are painstakingly developed by research in the purest realms of science.

Bush regarded basic research that informed national defense, employment, developing new products, and science education as contributing to the public welfare. He advocated for a basic research model that simultaneously satisfied the quests for exploration and held implications for application. This view anticipated the societal demands on

Donald A. Hantula

hantula@temple.edu

1 Temple University, Philadelphia, PA, USA 
scientists to solve pressing problems now - and the future be damned. Solely application-oriented research will expend scientific capital but will not replenish the fund with intellectual interest. Applied research that does not advance theory or knowledge beyond its application in question may be a short-term gain for the practitioner or researcher, but a long-term loss for science and the public welfare. ${ }^{1}$

The same dynamic plays out in behavior science and behavior analysis. It may be that the original applied and technological emphasis in Applied Behavior Analysis's (ABA) founding document (Baer, Wolf, \& Risley, 1968) was a stance adopted to differentiate ABA from the laboratory practices and fundamental science perspective of the experimental analysis of behavior (EAB; Cataldo, 2017). However, in the ensuing years, the applied and technological domain dominated, withdrawing hard-earned intellectual capital without much replenishment and placing cumbersome restrictions on research (Critchfield \& Reed, 2017; Friman, 2017)—a process dubbed baerwolfrisleyising (Critchfield, 2015). In his ABAI presidential address, Marr (2017) echoed Bush's (1945) concerns of a science depleted by application, observing that the effect has been exacerbated in the recent years because too few entering the field come in with adequate undergraduate preparation in mathematics and science. In Marr's words “. . . they are often appallingly ignorant of other natural sciences and, especially mathematics" (p. 203). Yet, some do not see a problem here, positing that perhaps the principle of positive reinforcement discovered through decades of basic research is sufficient for application (Baer, 1981), or that ABA and EAB have speciated as a natural consequence of changing social values (Rider, 1991) — c'est la vie. Others do see a problem and propose various schemes for translational research reminiscent of Bush's (1945) expanded definition of basic research (Critchfield, 2011; Kyonka \& Subramaniam, 2018; Mace \& Critchfield, 2010).

Unfortunately, translation takes time, and the twisted, steep, and thorny path from fundamental science to practical knowledge is revealed retrospectively. Only then does the "obvious" nonlinear development from research to application become clear. Imagine the response if Skinner and his early colleagues stepped out of their animal laboratories in the 1940s and told people that they were working on effective treatments for ASD, developmental delays, and psychological problems; methods to increase workplace performance and safety; procedures for improving education, better detection of land mines and tuberculosis, and solutions to problems of addiction. The reaction would be eyerolls and polite derision at best. A straight line from research to application is solely the province of second-rate children's television shows. A typical plotline that goes something like "Hark-Yonder lies an important social problem! A miasma of ominousness hath descended upon our fair town. Let us repair to the laboratory to find a solution!" After much scurrying about, involvement of people with

\footnotetext{
${ }^{1}$ This is the essence of long-standing criticism of Applied Behavior Analysis (ABA) and its overly technological focus (Cataldo, 2017; Critchfield \& Reed, 2017; Hayes, 1991; Lit \& Mace, 2015; Marr, 2017; Morris, 1991; Poling, 2010).

The astute reader may see that this as another example of delay discounting (Vanderveldt, Oliveira, \& Green, 2016), writ large; Marr made the same point. Ainslie (2001) argues that the constant tradeoff between a smaller-sooner outcome and a larger-later outcome is life's essential dilemma. Ainslie also observes that if we are sufficiently aware of this SS-LL choice dilemma, we can act in advance to make it more likely we will choose wisely in the moment, for example by engaging in actions such as policy statements and organizational procedures expressed by Bush (1945).
} 
unstylish clothing and bad haircuts, acquisition of apparatus (it is not science without apparatus) and cut to a commercial break, a solution is found. The solution is introduced to a grateful populace with copious polysyllabic nonsense, a fusillade of scientific terms (real science must be inscrutable), and some foreign phrases for flairall before suppertime.

If science does not deliver solutions, the culture will not support it. Vannevar Bush realized this and pointed to current, compelling, and concrete examples of important contributions that basic science made to public welfare to advance his arguments for government patronage of science and investment is training new scientists. In 1945, penicillin was a new lifesaving "miracle drug," radar revolutionized warfare, and the atomic bomb ended the War. ${ }^{2}$ These revolutionary solutions came from research in biological science, physical science, and nuclear science. Saving lives! Seeing across the horizon! Winning wars! Scientists solved problems. The path from lab to living room seemed much shorter then and the frontier probably did look endless. In 2019, the path may seem oblique, maybe nuanced, or a figment of collective wishful thinking, especially for behavior science. ${ }^{3}$

But as a nascent science, behavior science is working at a disadvantage here. Behavior science did not have the luxury of the extended inductive exploratory period that physical sciences enjoyed for centuries that allowed physical sciences to advance way beyond the seemingly effortless and obvious. Imagine the state of physical science today if instead of engaging in careful experimentation and quantitation the early physical scientists were confronted by a society that said, "Your balls, inclined planes, prisms and magnets are all quite interesting - but can you explain that nuclear reactor on the hill over there and tell us what to do about it?" Physical science is complicated; it is easier for most people to see a translation from basic research in physical science to an application; after all, few people are amateur physicists or chemists but everyone is an amateur psychologist, and as such psychology, behavior science, and behavior analysis may be regarded as little more than common sense enrobed in an academic gown.

On the other hand, if an application does not advance science and theory, the application will become a stale commodity for sale to the lowest bidder. An application may be based on science, but it may not necessarily contribute to that science. Reflect on the diversity of electronic consumer goods available today that would be miraculous a generation or two ago, but are now readily available. ${ }^{4}$ A phone that fits in your pocket and plays music on demand? A thin, crisp, clear TV the size of your front window? A

\footnotetext{
$\overline{2}$ Penicillin was discovered in 1928, first tested in humans in 1941, commercially produced in 1942, and manufactured in enough quantities to be distributed to pharmacies in 1945 (American Chemical Society \& the Royal Society of Chemistry, 1999). Radar as we know it came from an unsuccessful attempt to construct a death-ray device in 1934. A version of radar that could detect planes at night was developed in 1940, and is credited with helping win World War II (American Physical Society, 2006). Nuclear fission was discovered in 1938. The Manhattan Project, which produced the atomic bomb began in 1942 (Atomic Heritage Foundation, 2017).

${ }^{3}$ This also seems to have gotten longer for medical sciences. An analysis of "translation lag" (from discovery to use) for pharmaceuticals found a median of 24 years from discovery to first highly cited article, and a range of 0-28 years from first discovery to first human use and a range of 0-221 years from first discovery to first specific human use (Contopoulos-Ioannidis, Alexiou, Gouvias, \& Ioannidis, 2008).

${ }^{4}$ Consider a typical music playing greeting card that is available for less than US\$5.00. Personal experience shows that after 2-3 plays it becomes sufficiently annoying that it is not opened again, and remanded to the trash within a week, although this discard holds more computing power than all the Allied forces possessed in 1945 at the time Bush (1945) wrote his report (Kaku, 2011).
} 
speaker that requires no wires? An HVAC unit that adjusts itself based on who is in the house? Mobile phones, high-definition flat-screen televisions, Bluetooth speakers, "smart" thermostats are readily and cheaply available, and are jettisoned within 2-3 years. Indeed, many are built to be disposable and cannot be repaired. Marvels of science become landfill. Each of these devices solve a problem, but science moves on. Once a solution or application "works," it is no longer scientifically interesting.

However, in behavior science as well as in medical science, a science-application feedback loop appears to be more necessary (Kyonka \& Subramaniam, 2018). Perhaps it is because behavior science and medical science are not as highly developed as physical sciences and the solutions themselves are less robust, or perhaps it is because behavior science and medical science are tackling more difficult problems. This is especially the case when it comes to social problems. Social problems are often "wicked problems" (Mattaini, 2019; Rittel \& Webber, 1973). A wicked problem is one that occurs in a social context with a diversity of stakeholders, have no given alternative solutions, and in which an attempted solution changes the understanding of the problem; solutions are anything but linear and are rarely "right" or "wrong" but are "better" or "worse." When addressing a wicked problem, an iterative solution-science circuit is essential to first comprehend the problem, much less ameliorate it. Social problems are not rocket science. They are behavior science. They are more complex.

\section{The Wicked Problem of Addictions}

The heroic science of the mid-20 $0^{\text {th }}$ century solved many problems and saved countless lives. Yet the problem of addiction that bedeviled us in the $20^{\text {th }}$ century and centuries preceding it (White, 1998) was left unsolved. Addictions are a paradigmatic example of a wicked problem: they are a problem with farreaching social implications, a diverse array of stakeholders are involved, attempted solutions change understanding, and solutions seem to only make matters marginally better or worse. ${ }^{5}$ Addictions also highlight the woeful inadequacy of the technological-to-a-fault brand of $\mathrm{ABA}$ and the position that the principle of positive reinforcement discovered through decades of basic research is sufficient for application (Baer, 1981). Yes, drugs are reinforcers for many species, not only humans (Kearns, 2019). But that alone does not explain addiction; the majority of substance users do not develop a substance abuse problem or addiction. Why do only $14 \%$ of alcohol drinkers, $24 \%$ of tobacco smokers, and $7.5 \%$ of users of controlled substances or inhalants

\footnotetext{
${ }^{5}$ Beyond the well-known social ramifications of substance abuse, it has also been linked to a marked increase in mortality for middle-aged white and Latino men to the order of nearly 500,000 additional deaths (Case \& Deaton, 2015). Law enforcement, mental health practitioners, physicians, clergy, concerned laypeople, and legislators are among the stakeholders whose views on the issue are diverse, if not outright contradictory. For example, attitude change efforts such as DARE may increase use of alcohol and other drugs (Lillenfeld, 2007; Werch \& Owen, 2002), and solutions rooted in regarding addiction as a crime are seen to have made the problem worse (Werb, 2018), which led to a rethinking of addiction as disease (Leshner, 1997), a position that is now argued to be equally flawed and harmful (Levy, 2013; Lewis, 2015). According to Levy, addiction is a "disorder of a person within a social context," which makes the social context a necessary element of addiction and refutes the disease concept.
} 
develop dependence (Anthony, Warner, \& Kessler, 1994) $?^{6}$ An answer may be important to know if we endeavor to devise successful treatment, and even more important, successful prevention. This is not to say that positive reinforcement has no role in understanding or treating addiction-but it is not the apex of application. However, on a more hopeful note, recent research in behavior science and behavior analysis may provide a promising path to innovative, lifesaving solutions.

Understanding and solving the wicked problem of addictions requires research at the neural, individual, organizational, community, and population levels along with research in intervention, dissemination, and prevention. To showcase this work in behavior science ABAI organized a conference on addictions in November, 2018. The papers from that conference are featured in a special section of this issue, which was edited and artfully arranged by Wendy Donlin-Washington and Mark Galizio. These articles have much to offer everyone from experts to anyone even marginally interested in behavior science and behavior analysis. For those who work in or study behavioral pharmacology or addictions, this collection is an authoritative volume of the field's progress to date; indeed, it could be the backbone of a doctoral seminar. For other behavior scientists and behavior analysts, this special section strands as a testament to the power and scope of the science. From basic research in neural mechanisms and delay discounting to digital technology applications and large scale nationwide interventions, each article illustrates how basic research gave rise to effective application and how application loyal to the science informs further research and innovation. The path "from the lab bench to the park bench" is certainly not straight, but by all appearances it is taking us in the right direction. The outstanding work presented in this special section exemplifies "Behavior Science for the Public Welfare."

\section{Learning and Doing Better Science}

This issue includes a second special section on methodology that addresses two critical issues in behavior science and behavior analysis: reproducibility and quantitative sophistication. The first issue of Perspectives on Behavior Science (PoBS) of 2019 was dedicated to replication and reliability in research. The articles in that issue covered topics from an overview of the "replication crisis" (Hales, Wesselmann, \& Hilgard, 2019 ) to its implications for behavior science and analysis (Branch, 2019; Kaplan, Gilroy, Reed, Koffarnus, \& Hursh, 2019; Kyonka, 2019; Lanovaz, Turgeon, Cardinal, \& Wheatley, 2019; Laraway, Snycerski, Pradhan, \& Huitema, 2019; Perone, 2019; Tincani \& Travers, 2019). The articles in this special issue are not meant to be the final word on replication and reliability in research, but rather a call for a conversation (Hantula, 2019) as our scientific community works out its responses to the replication crisis and incorporates them into our culture.

\footnotetext{
${ }^{6}$ Promising studies using an operant choice procedure suggest that those rats in which the GABA transporter GAT-3 is decreased in the amygdala will select an alcohol solution over a more usually highly preferred saccharine solution (Augier et al., 2018; Augier et al., 2017). These "alcoholic" rats, whose behavior can be described as showing reduced sensitivity to alternative reinforcement, comprised around $15 \%$ of the sample. Decreased GAT-3 is also found in the amygdala of deceased adult human alcoholics.
} 
Encouraging more open-science practices is one action that came from the replication conversation and is now implemented within ABAI. The term "open science" (Nosek et al., 2015) has come to refer to a set of practices that advance transparency in research. These practices include making data, analytic methods, code, and protocols available and citable, and preregistration of research. In June 2019, the ABAI Publication Council adopted the following open science policy for all ABAI journals (currently Behavior Analysis in Practice, Behavior and Social Issues, Perspectives on Behavior Science, The Analysis of Verbal Behavior, The Psychological Record):

\section{Availability of Data, Protocols, Code, and Other Materials}

To facilitate dissemination and replicability, authors of papers published in ABAI journals are strongly encouraged to make data, protocols, computer code, analytic tools and other research materials (e.g., IOA sheets, procedural fidelity checklists, photographs of materials, videos) available in a public archive with persistent identifiers such as DOIs and accession numbers. Current options include appending supplemental material to an article hosted by Springer, a university library, GitHub, Databrary, FigShare. As data and materials sharing become more common other options will become available.

All empirical and methodological articles published in ABAI journals will be required to include a statement on Availability of Data, Protocols, Code, and Other Materials. This statement should specify what data and materials are available and how they may be accessed. If data and materials cannot be made publicly available, a rationale must be provided.

The particular means used to share data, code, and protocols matters much less than continuously engaging in open-science practices. PoBS has implemented these practices over the past few years and the options chosen by authors of articles in PoBS illustrate many of the choices available. For example, Springer can archive online supplementary material such as code (Bullock, Fisher, \& Hagopian, 2017) and video (Deochand, Costello, \& Deochand, 2018); materials may be archived in a university library (Kaplan et al., 2016) or on a public platform such as GitHub (Kaplan et al., 2019). It is readily recognized that using these kinds of repositories is a novel behavior for many behavior scientists and behavior analysts. In response, and in continuation of the conversation, Gilroy and Kaplan introduce GitHub as well as a well-illustrated practical tutorial on its use in behavioral research.

A cursory reading of the "replication crisis" literature may lead to uncritically blaming "statistics" for the disaster - and by extension indicting all forms of quantitation. Unfortunately, such a position overstates and misrepresents the problem. Of course, misuse of null hypothesis significance testing (NHST) based statistics, misinterpretations of its results, and misunderstanding its pretzel logic (Branch, 2019; Killeen, 2019) contribute to the crisis, but a wholesale rejection of "statistics" and quantitation is equally ignorant. "Mathematics is the language of science" is an aphorism attributed to Galileo, Hume, and Kant. Indeed, many of the major advances in behavior science such as the matching law, delay discounting, and behavioral momentum came about through quantitative analyses. Leading behavior scientists continue to push the boundaries of quantitation, as exemplified by the March 2019 
Special Issue of $J E A B$ on "Modern Statistical Practices in the Experimental Analysis of Behavior" (Young, 2019b). ${ }^{7}$ Of course, some of these analyses are difficult. Newland presents a tutorial on Information-Theoretic (I-T) Model Selection, an approach that ameliorates many of the problems of NHST and encourages examining multiple models. Weaver and Lloyd discuss use of randomization tests in analyzing data from SCRD studies. As they note, randomization tests may be especially well-suited to SCRD designs because these tests are flexible and do not rely on assumptions about normality and homoscedasticity. This article, along with other recent work (Killeen, 2019; Kyonka, 2019), also reinforces the idea that NHST based statistics are not anathema to behavior science and behavior analysis but can actually be helpful when used with discernment. Like many powerful things in this world, it is a question of proper use and misuse, not abolishment. Quantitation enables communication with other sciences; without communication, behavior science cannot contribute to the public welfare.

\section{Implications of Behavior Science}

The concluding two article in this issue explore social and scientific issues from a behavioral perspective. Rafacz analyzes healthy eating as choice behavior and reviews interventions for promoting selecting and consuming healthy foods. Of course, environmental modifications can change food choice (Sigurdsson, Larsen, \& Gunnarsson, 2014; Sigurdsson, Menon, \& Fagerstrøm, 2017) and nudge consumers towards more healthful choices. Behavior-based interventions may be particularly effective. A recent meta-analysis of healthy eating nudges in field settings found that effect size for what the authors termed "behaviorally oriented" nudges was over three times that of "cognitively oriented" nudges (Cadario \& Chandon, 2019). This is another example of how behavior science contributes to the public welfare. Finally, we address a fundamental question. What is science? Normand argues that science is what scientists do. Science is behavior and much of this behavior is verbal. To understand science then, one must understand the language of science. The corpus of this language is found in scientific journals, reports, and books in the form of text, which may be words, figures, graphs, numbers, and equations. And returning to Galileo, Hume, and Kant, some of the discourse is in the extraordinary language known as mathematics. By implication here, innumeracy in science is as limiting and destructive as illiteracy in science. Normand turns behavior science on behavior science and asks how do we know what we know? We know it when we say it. Something that we know and say about science is that it is a selfcorrecting process. Interrogations of science by scientists, especially behavior scientists, are among the most effective means for remedying past errors, preventing future imperfections, and advancing science for the public welfare.

\footnotetext{
${ }^{7}$ The breadth and depth of the papers in the JEAB Special Issue show a methodological expertise that belies the innumeracy and quantophobia that is sometimes seen as a trademark of "behavior analysis" (Craig \& Fisher, 2019; DeHart \& Kaplan, 2019; Elliffe \& Elliffe, 2019; Franck, Koffarnus, McKerchar, \& Bickel, 2019; Friedel, DeHart, Foreman, \& Andrew, 2019; Friedel, Galizio, Berry, Sweeney, \& Odum, 2019; Jacobs, 2019; Jensen, 2019; Kyonka, Mitchell, \& Bizo, 2019; Riley \& McDowell, 2019; Taylor, Elliffe, Podlesnik, \& Cowie, 2019; Villarreal et al., 2019; Young, 2019a).
} 
Acknowledgements Tom Critchfield, Erin Rasmussen, Dave Jarmolowicz and Ingunn Sandaker for their comments

\section{References}

Ainslie, G. (2001). Breakdown of will. New York, NY: Cambridge University Press.

American Chemical Society \& the Royal Society of Chemistry. (1999). The discovery and development of penicillin, 1928-1945. Retrieved from ht p s://ww w a s . org/content/dam/acsorg/education/whatischemistry/landmarks/flemingpenicillin/the-discovery-anddevelopment-of-penicillin-commemorative-booklet.pdf.

American Physical Society. (2006). This month in physics history April, 1935: British patent for radar system for air defense granted to Robert Watson-Watt. APS News, 15 (4). Retrieved from https://www.aps. org/publications/apsnews/200604/history.cfm.

Anthony, J. C., Warner, L. A., \& Kessler, R. C. (1994). Comparative epidemiology of dependence on tobacco, alcohol, controlled substances, and inhalants: Basic findings from the National Comorbidity Survey. Experimental \& Clinical Psychopharmacology, 2(3), 244.

Atomic Heritage Foundation. (2017). The Manhattan Project. Retrieved from https:/www.atomicheritage. org/history/manhattan-project.

Augier, E., Barbier, E., Dulman, R. S., Licheri, V., Augier, G., Domi, E., et al. (2018). A molecular mechanism for choosing alcohol over an alternative reward. Science, 360(6395), 1-6. https://doi.org/10.1126/science. aao1157.

Augier, E., Dulman, R. S., Damadzic, R., Pilling, A., Hamilton, J. P., \& Heilig, M. (2017). The GABAB positive allosteric modulator ADX71441 attenuates alcohol self-administration and relapse to alcohol seeking in rats. Neuropsychopharmacology, 42(9), 1789-1799. https://doi.org/10.1038/npp.2017.53.

Baer, D., Wolf, M., \& Risley, T. (1968). Some current dimensions of applied behavior analysis. Journal of Applied Behavior Analysis, 1, 91-97 Retrieved from http://libproxy.temple.edu/login?url=http://search. ebscohost.com/login.aspx $?$ direct $=$ true $\& d b=$ psyhref $\& A N=J A B A . A . I A . B A E R . S C D A B A \&$ site $=$ ehostlive \&scope $=$ site.

Baer, D. M. (1981). A flight of behavior analysis. The Behavior Analyst, 4(2), 85-91. https://doi.org/10.1007 /bf03391857.

Branch, M. N. (2019). The "reproducibility crisis": Might the methods used frequently in behavior-analysis research help? Perspectives on Behavior Science, 42(1), 77-89. https://doi.org/10.1007/s40614-0180158-5.

Bullock, C. E., Fisher, W. W., \& Hagopian, L. P. (2017). Description and validation of a computerized behavioral data program: "BDataPro.". The Behavior Analyst, 40(1), 275-285. https://doi.org/10.1007 /s40614-016-0079-0.

Bush, V. (1945). Science-The endless frontier: A report to the president on a program for postwar scientific research. Washington, DC: National Science Foundation.

Cadario, R., \& Chandon, P. (2019). Which healthy eating nudges work best? A meta-analysis of field experiments. Marketing Science. https://doi.org/10.1287/mksc.2018.1128.

Case, A., \& Deaton, A. (2015). Rising morbidity and mortality in midlife among white non-Hispanic Americans in the 21st century. Proceedings of the National Academy of Sciences, 112(49), 15078-15083.

Cataldo, M. F. (2017). Driving with the rear view mirror. The Behavior Analyst, 40(1), 161-165. https://doi. org/10.1007/s40614-017-0103-z.

Contopoulos-Ioannidis, D. G., Alexiou, G. A., Gouvias, T. C., \& Ioannidis, J. P. (2008). Life cycle of translational research for medical interventions. In American Association for the Advancement of Science.

Craig, A. R., \& Fisher, W. W. (2019). Randomization tests as alternative analysis methods for behavioranalytic data. Journal of the Experimental Analysis of Behavior, 111(2), 309-328. https://doi.org/10.1002 jjeab.500.

Critchfield, T. S. (2011). Translational contributions of the experimental analysis of behavior. The Behavior Analyst, 34(1), 3-17. https://doi.org/10.1007/bf03392227.

Critchfield, T. S. (2015). PBIS may not qualify as classical applied behavior analysis So what? Behavior Analysis in Practice, 8(1), 99-100. https://doi.org/10.1007/s40617-015-0048-1.

Critchfield, T. S., \& Reed, D. D. (2017). The fuzzy concept of applied behavior analysis research. The Behavior Analyst, 40(1), 123-159. https://doi.org/10.1007/s40614-017-0093-x. 
DeHart, W. B., \& Kaplan, B. A. (2019). Applying mixed-effects modeling to single-subject designs: An introduction. Journal of the Experimental Analysis of Behavior, 111(2), 192-206. https://doi.org/10.1002 jeab.507.

Deochand, N., Costello, M. S., \& Deochand, M. E. (2018). Behavioral research with planaria. Perspectives on Behavior Science, 41(2), 447-464. https://doi.org/10.1007/s40614-018-00176-w.

Elliffe, D., \& Elliffe, M. (2019). Rank-permutation tests for behavior analysis, and a test for trend allowing unequal data numbers for each subject. Journal of the Experimental Analysis of Behavior, 111(2), 342358. https://doi.org/10.1002/jeab.502.

Franck, C. T., Koffarnus, M. N., McKerchar, T. L., \& Bickel, W. K. (2019). An overview of Bayesian reasoning in the analysis of delay-discounting data. Journal of the Experimental Analysis of Behavior, 111(2), 239-251. https://doi.org/10.1002/jeab.504.

Friedel, J. E., DeHart, W. B., Foreman, A. M., \& Andrew, M. E. (2019a). A Monte Carlo method for comparing generalized estimating equations to conventional statistical techniques for discounting data. Journal of the Experimental Analysis of Behavior, 111(2), 207-224. https://doi.org/10.1002/jeab.497.

Friedel, J. E., Galizio, A., Berry, M. S., Sweeney, M. M., \& Odum, A. L. (2019b). An alternative approach to relapse analysis: Using Monte Carlo methods and proportional rates of response. Journal of the Experimental Analysis of Behavior, 111(2), 289-308. https://doi.org/10.1002/jeab.489.

Friman, P. C. (2017). You are in the way! Opening lines of transmission for Skinner's view of behavior. The Behavior Analyst, 40(1), 173-177. https://doi.org/10.1007/s40614-017-0095-8.

Hales, A. H., Wesselmann, E. D., \& Hilgard, J. (2019). Improving psychological science through transparency and openness: An overview. Perspectives on Behavior Science, 42(1), 13-31. https://doi.org/10.1007 /s40614-018-00186-8.

Hantula, D. A. (2019). Editorial: Replication and reliability in behavior science and behavior analysis: A call for a conversation. Perspectives on Behavior Science, 42(1), 1-11. https://doi.org/10.1007/s40614-01900194-2.

Hayes, S. C. (1991). The limits of technological talk. Journal of Applied Behavior Analysis, 24(3), 417-420. https://doi.org/10.1901/jaba.1991.24-417.

Jacobs, K. W. (2019). Replicability and randomization test logic in behavior analysis. Journal of the Experimental Analysis of Behavior, 111(2), 329-341. https://doi.org/10.1002/jeab.501.

Jensen, G. (2019). Instrumental variable estimation of reinforcer effects. Journal of the Experimental Analysis of Behavior, 111(2), 359-368. https://doi.org/10.1002/jeab.498.

Kaku, M. (2011). Physics of the future: How science will shape human destiny and our daily lives by the year 2100. New York, NY: Doubleday.

Kaplan, B. A., Amlung, M., Reed, D. D., Jarmolowicz, D. P., McKerchar, T. L., \& Lemley, S. M. (2016). Automating scoring of delay discounting for the 21- and 27-item Monetary Choice Questionnaires. The Behavior Analyst, 39(2), 293-304. https://doi.org/10.1007/s40614-016-0070-9.

Kaplan, B. A., Gilroy, S. P., Reed, D. D., Koffarnus, M. N., \& Hursh, S. R. (2019). The R package beezdemand: Behavioral Economic Easy Demand. Perspectives on Behavior Science, 42(1), 163-180. https://doi.org/10.1007/s40614-018-00187-7.

Kearns, D. N. (2019). The effect of economy type on reinforcer value. Behavioural Processes, 162, $20-28$. https://doi.org/10.1016/j.beproc.2019.01.008.

Killeen, P. R. (2019). Predict, control, and replicate to understand: How statistics can foster the fundamental goals of science. Perspectives on Behavior Science, 42(1), 109-132. https://doi.org/10.1007/s40614-0180171-8.

Kyonka, E. G. E. (2019). Tutorial: Small-N power analysis. Perspectives on Behavior Science, 42(1), 133152. https://doi.org/10.1007/s40614-018-0167-4.

Kyonka, E. G. E., Mitchell, S. H., \& Bizo, L. A. (2019). Beyond inference by eye: Statistical and graphing practices in JEAB, 1992-2017. Journal of the Experimental Analysis of Behavior, 111(2), 155-165. https://doi.org/10.1002/jeab.509.

Kyonka, E. G. E., \& Subramaniam, S. (2018). Translating behavior analysis: A spectrum rather than a road map. Perspectives on Behavior Science, 41(2), 591-613. https://doi.org/10.1007/s40614-018-0145-x.

Lanovaz, M. J., Turgeon, S., Cardinal, P., \& Wheatley, T. L. (2019). Using single-case designs in practical settings: Is within-subject replication always necessary? Perspectives on Behavior Science, 42(1), 153162. https://doi.org/10.1007/s40614-018-0138-9.

Laraway, S., Snycerski, S., Pradhan, S., \& Huitema, B. E. (2019). An overview of scientific reproducibility: Consideration of relevant issues for behavior science/analysis. Perspectives on Behavior Science, 42(1), 33-57. https://doi.org/10.1007/s40614-019-00193-3.

Leshner, A. I. (1997). Addiction is a brain disease, and it matters. Science, 278(5335), 45-47.

Levy, N. (2013). Addiction is not a brain disease (and it matters). Frontiers in Psychiatry, 4, 24. 
Lewis, M. (2015). The biology of desire: Why addiction is not a disease. Hachette.

Lillenfeld, S. O. (2007). Psychological treatments that cause harm. Perspectives on Psychological Science. 2, 53-70.

Lit, K., \& Mace, F. C. (2015). Where would ABA be without EAB? An example of translational research on recurrence of operant behavior and treatment relapse. Revista Mexicana de Análisis de la Conducta, 41(2), 269-288.

Mace, F. C., \& Critchfield, T. S. (2010). Translational research in behavior analysis: historical traditions and imperative for the future. Journal of the Experimental Analysis of Behavior, 93(3), 293-312. https://doi. org/10.1901/jeab.2010.93-293.

Marr, M. J. (2017). The future of behavior analysis: Foxes and hedgehogs revisited. The Behavior Analyst, 40(1), 197-207. https://doi.org/10.1007/s40614-017-0107-8.

Mattaini, M. A. (2019). Out of the lab: Shaping an ecological and constructional cultural systems science. Perspectives on Behavior Science. https://doi.org/10.1007/s40614-019-00208-z.

Morris, E. K. (1991). Deconstructing “technological to a fault.” Journal of Applied Behavior Analysis, 24(3), 411-416. doi:https://doi.org/10.1901/jaba.1991.24-411

Nosek, B. A., Alter, G., Banks, G. C., Borsboom, D., Bowman, S. D., Breckler, S. J., et al. (2015). Promoting an open research culture. Science, 348(6242), 1422. https://doi.org/10.1126/science.aab2374.

Perone, M. (2019). How I learned to stop worrying and love replication failures. Perspectives on Behavior Science, 42(1), 91-108. https://doi.org/10.1007/s40614-018-0153-x.

Pielke, R., Jr. (2010). In Retrospect: Science-The endless frontier. Nature, 466, 922. https://doi.org/10.1038 /466922a.

Poling, A. (2010). Looking to the future: Will behavior analysis survive and prosper? The Behavior Analyst, 33(1), 7-17. https://doi.org/10.1007/bf03392200.

Rider, D. P. (1991). The speciation of behavior analysis. The Behavior Analyst, 14(2), 171-181. https://doi. org/10.1007/BF03392567.

Riley, S., \& McDowell, J. J. (2019). The WIG (weighted individual and group) shrinkage estimator. Journal of the Experimental Analysis of Behavior, 111(2), 166-182. https://doi.org/10.1002/jeab.503.

Rittel, H. W. J., \& Webber, M. M. (1973). Dilemmas in a general theory of planning. Policy Sciences, 4(2), 155-169. https://doi.org/10.1007/BF01405730.

Sigurdsson, V., Larsen, N. M., \& Gunnarsson, D. (2014). Healthy food products at the point of purchase: An in-store experimental analysis. Journal of Applied Behavior Analysis, 47(1), 151-154.

Sigurdsson, V., Menon, R. G. V., \& Fagerstrøm, A. (2017). Online healthy food experiments: Capturing complexity by using choice-based conjoint analysis. The Behavior Analyst, 40(2), 373-391. https://doi. org/10.1007/s40614-017-0114-9.

Taylor, R., Elliffe, D., Podlesnik, C. A., \& Cowie, S. (2019). The nanoeconomics of concurrent choice behavior. Journal of the Experimental Analysis of Behavior, 111(2), 274-288. https://doi.org/10.1002 /jeab.508.

Tincani, M., \& Travers, J. (2019). Replication research, publication bias, and applied behavior analysis. Perspectives on Behavior Science, 42(1), 59-75. https://doi.org/10.1007/s40614-019-00191-5.

Vanderveldt, A., Oliveira, L., \& Green, L. (2016). Delay discounting: Pigeon, rat, human - does it matter? Journal of Experimental Psychology: Animal Learning \& Cognition, 42(2), 141-162. https://oi. org/10.1037/xan0000097.

Villarreal, M., Velázquez, C., Baroja, J. L., Segura, A., Bouzas, A., \& Lee, M. D. (2019). Bayesian methods applied to the generalized matching law. Journal of the Experimental Analysis of Behavior, 111(2), 252273. https://doi.org/10.1002/jeab.506.

Werb, D. (2018). Post-war prevention: Emerging frameworks to prevent drug use after the War on Drugs. International Journal of Drug Policy, 51, 160-164. https://doi.org/10.1016/j.drugpo.2017.06.012.

Werch, C.E., \& Owen, D. (2002). Iatrogenic effects of alcohol and drugprevention programs.Journal of Studies on Alcohol, 63, 581-590.

White, W. L. (1998). Slaying the dragon: The history of addiction treatment and recovery in America. Bloomington, IL: Chestnut Health Systems/Lighthouse Institute.

Young, M. E. (2019a). Bayesian data analysis as a tool for behavior analysts. Journal of the Experimental Analysis of Behavior, 111(2), 225-238. https://doi.org/10.1002/jeab.512.

Young, M. E. (2019b). Modern statistical practices in the experimental analysis of behavior: An introduction to the special issue. Journal of the Experimental Analysis of Behavior, 111(2), 149-154. https://doi. org/10.1002/jeab.511.

Publisher's Note Springer Nature remains neutral with regard to jurisdictional claims in published maps and institutional affiliations. 